\title{
Reclaiming Lost Territory: The Response of Owyhee Harvester Ants to Forager Intrusions by Neighboring Colonies
}

\author{
Brett D. Howell: McNair Scholar \\ Dr. Ian Robertson: Mentor \\ Biological Science
}

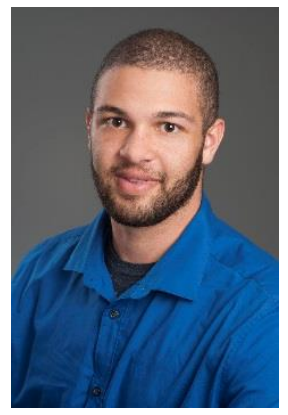

\begin{abstract}
Neighboring colonies of the Owyhee harvester ant, Pogonomyrmex salinus, often share non-overlapping foraging boundaries in the areas between their nests. We found that interactions between neighbors along these foraging boundaries were infrequent but peaceful, and usually resulted in one or both individuals becoming agitated and scurrying away in opposite directions. Interactions between neighbors were necessary to maintain the foraging ranges of their respective colonies. An exclusion experiment showed that when one colony of a pair situated 5-7 $m$ apart was denied access to its foraging range, individuals from the other colony would usually (i.e., in 7 out of 10 cases) enter the unoccupied space within one day. In 6 of 7 of those cases the occupiers set up foraging trails in the newly acquired area in 5 to 39 days (median $=13$ days). When foragers from the excluded colony were subsequently allowed access to their original foraging area, they reclaimed the entire area within 11 days but did not extend their advances beyond the original foraging boundaries. In contrast to the earlier encounters between neighbors, encounters during the reacquisition period were always aggressive, and in 14 of 57 encounters one or

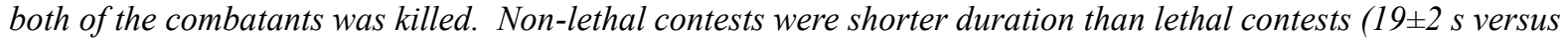
$422 \pm 65 \mathrm{~s}$, respectively). Our results show that competition for foraging space in Owyhee harvester ants is intense despite the seemingly peaceful relationship between neighboring colonies prior to perturbation of their foraging boundaries. Keywords: Pogonomyrmex salinus, harvester ants, territorial behavior, foraging ranges, intercolony aggression
\end{abstract}

\section{Introduction}

Competition for resources often defines the interactions of neighbors and how they partition space. Many organisms actively maintain territorial boundaries by defending resources or attacking intruders that enter their range. The ability to establish and maintain a territory ('resource holding potential'), and the value of a territory to a holder relative to a challenger ('pay-off or value asymmetry'), are expected to influence the formation of territorial boundaries and the outcome of territorial disputes (Parker 1974; Maynard Smith and Parker 1976).

Food is a limiting resource for many desert granivores, including seed harvesting ants in the genus Pogonomyrmex (Brown and Davidson 1977; Davidson 1977, 1985). Competition for foraging space between neighboring harvester ant colonies is often cited as an important influence on the spatial distributions of nests, at least at smaller spatial scales (Hölldobler 1976; De Vita 1979; Levings and Traniello 1981; Ryti and Case 1988, 1992; Wiernasz and Cole 1995; Crist and Wiens 1996, Gordon 1991, 1992, Gordon and Kulig 1996, 1998; Adler and Gordon 2003). Individual foragers travel to and from their nest along habitual foraging trails that typically radiate up to $20 \mathrm{~m}$ away from the nest, sometimes farther, and gradually dissipate into resource patches where foragers search for food (Gordon 1991, 1995; MacMahon et al. 2000). In some cases these trails exist as narrow visible clearings of vegetation, or "trunk trails" (Hölldobler 1976). Encounters between individuals from neighboring colonies, which occur most often at the distant edges of foraging areas, determine the boundaries of their respective territories. Frequent interaction with neighbors is needed to maintain these boundaries (Gordon 1992).

Examples of territorial exclusion and intraspecific aggression between ants from neighboring colonies are not uniform across Pogonomyrmex species. Aggressive, and sometimes lethal contests have been reported in $P$. californicus (De Vita 1979), P. rugosus, P. maricopa (Hölldobler 1976), P. mayri (Kugler 1984), and P. barbatus (Hölldobler 1976; Gordon 1992, 1995; Gordon and Kulig 1996). By contrast, Harrison and Gentry (1981) observed overlapping foraging ranges and no aggressive interactions among neighboring $P$. badius colonies; chance encounters between neighbors were brief and resulted in little more than mutual agitation (Harrison and Gentry 
1981). Similarly, Porter and Jorgensen (1981) and Jorgensen and Porter (1982) observed no aggressive encounters between neighboring $P$. owyheei (a species now accepted as $P$. salinus Olsen, as interpreted by Shattuck 1987) colonies. Whitford (1976) reported no cases of intercolony aggression in P. rugosus, in contrast to the observations of Hölldobler (1976). Gordon and Kulig (1996) report that encounters between members of the same neighboring $P$. barbatus colonies may lead to fights on one day but not on another. Such differences in the observed occurrence of fighting within and among species may reflect differences in the circumstances that promote aggression among neighbors rather than species' specific tendencies toward aggression. For example, younger (3 to 4-yr old) colonies of P. barbatus are more prone to inter-colony aggression than older colonies (Gordon 1991, 1992), and foragers react more strongly to encounters with ants from neighboring colonies than more distant colonies, likely because the latter represent less of a threat to the integrity of foraging boundaries (Gordon 1989).

Here we investigate the nature of encounters between neighboring colonies of Owyhee harvester ants, Pogonomyrmex salinus, both before and after perturbing established foraging boundaries of closely situated colonies. Using an approach similar to that of Gordon (1992), we conducted an exclusion experiment to determine whether $P$. salinus foragers would move into a neighboring colony's foraging range if it was left unoccupied, and whether these individuals could then hold the area once the neighbor was once again permitted access. Much like Gordon (1992) found for P. barbatus, P. salinus readily moved into newly vacant foraging areas, but were unable to hold these areas when the original occupants regained access. These changes in ownership promoted the escalation of contests between neighbors, including lethal encounters.

\section{Methods}

Pogonomyrmex ants are common seed predators throughout arid and semiarid regions of the Americas, including sagebrush-steppe habitat in the Great Basin of North America. Their large, conical nests often dot the landscape and typically range in density from 10-80 colonies/ha (MacMahon et al. 2000). Individual colonies may survive for more than 20 years (Porter and Jorgensen 1988; MacMahon et al. 2000) as long as the founding queen survives and continues to lay eggs (Gordon 1991). In temperate climates harvester ants forage diurnally from spring to autumn whenever surface temperatures are sufficiently warm. Foragers gather large numbers of seeds from the ground, as well as insects, soil particles, and vegetation (Tabor 1998). Pogonomyrmex salinus is the northernmost member of the genus, and occurs from southwestern Canada through Idaho, Washington, Oregon, northeastern California, Nevada, and western portions of Utah, Montana, and Wyoming (Cole 1968; Tabor 1998). Population densities as high as 164 colonies per hectare have been recorded (Blom et al. 1991), although lower densities are more typical (Porter and Jorgensen 1988; Blom et al. 1991; Robertson 2015).

We conducted our study from early June to early September 2014 at a population of harvester ants located in disturbed sagebrush-steppe habitat near Melba, Idaho. The density of ant colonies at the site was approximately 30/ha. Vegetation consisted primarily of Poa secunda (Sandberg bluegrass), Bromus tectorum (cheatgrass), Sisymbrium altissimum (tumble mustard), and limited amounts of Artemisia tridentata (big sagebrush). Earlier work on this population of ants (Schmasow 2015) found that the ants focused their foraging on P. secunda and $S$. altissimum seeds, as well as seeds of a rare mustard when available.

Ten pairs of colonies were included in the study. Seven pairs were selected in June, and three more pairs were added in mid to late August. The two colonies that made up each pair were located $5-7 \mathrm{~m}$ from one another $($ mean $\pm \mathrm{SE}=5.8 \pm 0.2 \mathrm{~m})$, and all pairs were located at least $40 \mathrm{~m}$ apart to ensure independence of samples. The main criteria for selecting pairs, apart from the short distance between colonies, was that ants from both colonies foraged in at least portions of the area directly between the two nests, and that these areas abutted one another to form a foraging boundary between colonies. Although we do not know the specific ages of the colonies used in our experiment, all were at least two years old based on the size of the nest mounds and associated clearings around their perimeter (1-year old $P$. salinus nests are relatively small and lack a prominent cleared area around the perimeter [ICR, unpublished data]).

We mapped the foraging areas of each colony over a period of several days to a week, and while doing so watched for and noted any interactions between neighbors along shared foraging boundaries. Observations were made between 0830 and noon, or until rising temperature caused the ants to withdraw into their nests. To establish a colony's foraging boundaries we followed foragers as they moved away from their nest and marked with a small flag their most distant position from the nest. We designated the colony whose foraging range extended beyond the midpoint of the two colonies as the "alpha" and the other as the "beta"; however, no dominance hierarchy or relative measure of colony size is implied by these designations. On average, the foraging boundaries of alpha colonies extended $0.9 \pm 0.2 \mathrm{~m}$ (range $=0-2.0 \mathrm{~m}$ ) past the midpoint of the two colonies. In the two cases where the colonies 
met at the midpoint, we flipped a coin to establish which would be designated the alpha. There was no significant difference in the total foraging areas of alpha versus beta colonies (Paired t-test, $t_{9}=0.405, p=0.69$ ).

Once we established the foraging boundaries for both colonies of a pair, we installed a barrier that prevented the alpha colony from accessing its foraging range in the intervening space between the colonies. The barrier, which was placed within $0.5 \mathrm{~m}$ of the alpha nest, consisted of $13 \mathrm{~cm}$ high black plastic garden edging staked firmly to the ground in a 2-4 $\mathrm{m}$ arc that redirected alpha foragers away from the beta colony. We installed the barriers early in the morning, prior to the start of active foraging. In cases where ants were observed skirting around the barrier, we extended the barrier with up to $3 \mathrm{~m}$ of additional edging. If ants burrowed beneath the barrier we filled and packed the breach with soil immediately upon discovery. These measures were successful in denying foragers from alpha colonies access to the territory they once occupied in the area between nests.

One day after a barrier was erected and its effectiveness confirmed we began daily observations to record changes to the foraging boundaries of both the beta and alpha colony. As before, we used flags to map the boundaries. Incursions by beta foragers into the area previously occupied by the alpha colony were of particular interest. We noted the timing of formation of habitual foraging trails, which we defined as narrow $(\sim 20 \mathrm{~cm}$ wide) pathways used by 40 or more beta colony ants over a span of 2 minutes when foragers were active in the area (see Gordon [1992] for a similar metric used to define the foraging trails of P. barbatus).

If and when beta foragers formed a foraging trail into the area previously held by the alpha colony, we removed the barrier within two days. We then returned daily to remap the foraging boundaries of each colony and assess whether the alpha colony reclaimed the foraging range it had previously occupied. During this time we also watched for and noted encounters between ants from opposing colonies. Aggressive encounters, i.e., those that involved biting and physical tussling between individuals, were scored either as non-lethal (to both combatants) or lethal (to one or both combatants). We recorded the outcomes of aggressive encounters, and the duration of those for which we were present from the start of the interaction.

\section{Results}

We observed no instances of overlap in the foraging ranges of neighboring colonies during our mapping of boundaries, nor did we witness any aggressive contests along shared boundaries between neighbors. Neighbors active in the same general area (i.e., $<30 \mathrm{~cm}$ apart) along shared borders seldom came in direct physical contact with one another. On the few occasions we did observe encounters between neighbors ( $\mathrm{N}=10$ across all nest pairs), the interactions were brief $(<1 \mathrm{~s})$, and immediately afterward the individuals scurried away in an agitated manner for several seconds before resuming normal foraging activity within their respective territories.

Three of the 10 pairs of colonies showed no change in the beta colony's foraging boundary after a barrier was placed near the alpha colony. These three pairs were the ones we added to the study in mid to late August, and they were not manipulated further. In the remaining seven cases, all of which were set up in June, foragers from the beta colony were observed foraging in the newly available terrain one day after the barrier was erected. In all but one of these cases the beta foragers established a foraging trail into their newly acquired foraging area, although the timing of trail establishment varied among colonies (Table 1).

Removal of the barriers triggered a rapid response by alpha colonies - alpha foragers entered their previously held territory within one day in all six cases in which the barrier was removed. Complete recovery of these foraging areas occurred 3-11 days after the barriers were removed (Table 2). Foraging trails used by beta foragers were abandoned quickly once the alpha foragers returned. Alpha foragers did not advance beyond the original boundaries of their reclaimed foraging areas (Fig 1).

During the period of territory reacquisition by alpha colonies, we did not observe any of the brief, uneventful interactions that had characterized encounters between neighbors prior to perturbation of their foraging territories. However, we did observe aggressive encounters between neighbors at five of the six pairs of colonies (Table 3). A total of 57 aggressive encounters were observed, 45 of which occurred along the foraging boundary of the colonies of nest pair C. Of those 45 encounters, 11 resulted in the death of one or both combatants. At four of the other five nest pairs we recorded a total of 12 contests, two of which were lethal. No contests were observed at pair D; however, because contests in general were sporadically timed and often brief, they may have occurred undetected. Non-lethal contests were significantly briefer than lethal contests (Fig 2, t-test: $t_{33}=8.09, \mathrm{p}<0.0001$ ), and never lasted more than 43 seconds (mean duration $18.5 \mathrm{~s}$, median $15.9 \mathrm{~s}$, range $5-43 \mathrm{~s}$ ). When contests lasted more than 4 minutes (i.e., in 11 of the 13 lethal contests that we timed from start to finish: mean duration 7.0 min, median $6.1 \mathrm{~min}$, range $=4.0-14.9 \mathrm{~min}$ ), both combatants died while locked in a mutual death grip. Because observations of contests between neighbors were opportunistic, differences in the number of aggressive interactions 
among colony pairs may not reflect actual differences. Instead, the numbers serve to document the occurrence, intensity and consequences of individual contests between neighbors.

\section{Discussion}

Owyhee harvester ants compete with neighboring colonies for access to foraging areas, and in some cases encounters between neighbors in disputed territory prove lethal to one or both combatants. Aggressive interactions between individual foragers of neighboring colonies are frequently reported in Pogonomyrmex ants (Hölldobler 1976; De Vita 1979; Kugler 1984; Gordon 1992; Gordon and Kulig 1996) as well as other territorial ant species (Haering and Fox 1987; Adams 1990; Tschinkel et al. 1995; Brown and Gordon 2000). To our knowledge ours is the first account of aggressive and sometimes lethal encounters between neighboring P. salinus $(P$. owyheei) colonies. Earlier studies indicated that $P$. salinus foragers do not engage in aggressive contests with neighbors, even in the few instances in which the foraging ranges of neighboring colonies overlapped (Porter and Jorgensen 1981, Jorgensen and Porter 1982). However, it is not clear from those studies whether neighbors used their overlapping foraging ranges simultaneously. In Pogonomyrmex ants, patrollers set the foraging direction for workers from their respective colonies on a daily basis (Greene and Gordon 2007), and in doing so limit simultaneous use when foraging ranges overlap (Gordon 1991; Gordon and Kulig 1996). Distance between colonies may also play a role. The likelihood of aggressive interactions between neighbors decreases as a function of distance between colonies (Hölldobler 1976; Gordon and Kulig 1996), and in the present study neighboring colonies were situated particularly close to one another and thus may have increased the likelihood of aggressive encounters along foraging boundaries.

The nature of aggressive encounters in P. salinus follows the same pattern Gordon and Kulig (1996) report for $P$. barbatus. Most encounters between neighbors are non-lethal, and non-lethal contests are much shorter in duration than lethal contests. As a cautionary note, because aggressive encounters lasted longer and thus were more likely to be observed than non-lethal contests, the incidence of lethal contests $(24.6 \%)$ relative to non-lethal contests may be overestimated in our study. Nevertheless, the regular occurrence of lethal contests attests to the intensity of competition for foraging space among neighbors. Although the cost of intercolony conflict over the course of a season may be small relative to other costs such as predation (Gordon and Kulig 1996), competition for foraging space is clearly an important driver of intercolony interactions.

As with most behavioral interactions, context is important in determining whether encounters between neighboring harvester ants will escalate into aggressive contests. Prior to experimental manipulation of colony foraging ranges we did not observe any overt aggression between neighbors along their foraging boundaries, similar to the observations of Jorgensen and Porter (1982 - P. salinus) and Gordon (1991 - P. barbatus). Instead, occasional encounters between neighbors along foraging boundaries resulted in one or both individuals becoming agitated and scurrying away in opposite directions, much like Harrison and Gentry (1981) describe for P. badius. Such uneventful encounters between neighbors may serve to reinforce the boundaries of foraging ranges between longstanding neighbors without costly escalation to either colony (Harrison and Gentry 1981; Jorgensen and Porter 1982; Gordon 1991).

Absence of aggressive encounters along shared boundaries is not evidence of a lack of competition for space between neighboring colonies. To the contrary, a case is growing for the importance of regular interactions among neighbors to establish and maintain the integrity of territorial boundaries in harvester ants (Harrison and Gentry 1981; Kugler 1984; Gordon 1992; Brown and Gordon 2000) and other territorial ants species (Adams 1990; 2003), although Whitford (1976) argues this is not the case in P. rugosus (but see Hölldobler 1976). In the absence of regular encounters with their neighbors, $P$. salinus usually occupied their neighbor's foraging range in short order; in 7 of 10 cases foragers from the beta colony entered the alpha colony's foraging range within one day of the alpha colony being excluded. In six of those cases foraging trails into the areas were eventually established, confirming that the areas were being exploited for food. Variability in the timing of establishment of foraging trails (i.e., 5-39 days) may reflect differences in the value of new foraging areas relative to other areas within a colony's foraging range. For example, spatiotemporal patchiness in the availability of seeds within a colony's foraging range may influence the extent of forager recruitment into specific areas (Gordon 1991), including newly acquired territory.

The three cases in which the beta colony did not enter the alpha colony's range were unique in that the barriers were erected late in the study (i.e., mid-late August) rather than in June and early July, as was the case for the others. Because harvester ant colonies compete for space in which to search for seeds, not for areas of consistently high food value (Gordon 1993), it is unlikely that the lack of response by these colonies was related to the quality or quantity of food in the unoccupied areas. Instead, the lack of response may reflect seasonal shifts in 
the allocation of workers to foraging. In P. badius, the percent of each colony allocated to foraging peaks during maximal larval production in early to mid summer, and then declines steadily as the season progresses (Kwapich and Tschinkel 2013). If a similar pattern of labor allocation occurs in P. salinus, the availability of foragers late in the summer may not have been sufficient for beta colonies to occupy and maintain new foraging areas.

Although historical ownership of a foraging area did not deter occupation by ants from beta colonies once the area was left undefended, it did influence the outcome of efforts by the alpha colony to reclaim the space. As Gordon (1992) found for P. barbatus, we found that $P$. salinus either retreated or were driven from their newly acquired foraging areas once the neighboring alpha colony was allowed access. The alpha colony's familiarity with its original foraging area, or the proximity of this foraging area to its nest, may outweigh any squatter's advantage the intruding beta colony accrued while occupying the space. On the other hand, the asymmetric design of our experiment leaves open the possibility that alpha colonies (i.e., colonies whose initial foraging range extended past the midpoint of their paired neighboring colony) were able to reclaim lost territory because they were dominant over their beta counterparts. Interestingly, alpha colonies were only able to recover previously held foraging areas; their advances did not extend beyond the boundaries of their original territory. Perhaps beta colonies had an advantage in holding the foraging areas they were more familiar with, or whose value was elevated because of proximity to their nests. It would be interesting to conduct an experiment in which both the alpha and beta colonies of a pair are denied access to their respective foraging areas in alternating turns. Do both colonies hold an advantage in recovering their historical foraging ranges, or is one colony dominant over the other in terms of resource holding potential? Such an experiment would help clarify the dynamics associated with the formation and maintenance of foraging boundaries between neighboring harvester ant colonies.

\section{Acknowledgments}

We thank Michelle Jeffries for assistance in the field, Boise State University and the McNair Scholars Program for funding, and Michelle Jeffries, Matt Schmasow, and two anonymous reviewers for helpful comments on the manuscript.

\section{References}

Adams ES (1990) Boundary disputes in the territorial ant Azteca trigona: effects of asymmetries in colony size. Anim Behav 39:321-328

Adams ES (2003) Experimental analysis of territory size in a population of the fire ant Solenopsis invicta. Behav Ecol 14:48-53

Adler FR, Gordon DM (2003) Optimization, conflict, and nonoverlapping foraging ranges in ants. Am Nat 162:529543

Blom PE, Clark WH, Johnson JB (1991) Colony densities of the seed harvesting ant Pogonomyrmex salinus (Hymenoptera: Formicidae) in seven plant communities on the Idaho National Engineering Laboratory. J Idaho Acad Sci 27:28-36

Brown JH, Davidson DW (1977) Competition between seed-eating rodents and ants in desert ecosystems. Science 196-880-882

Brown MJF, Gordon DM (2000) How resources and encounters affect the distribution of foraging activity in a seedharvesting ant. Behav Ecol Sociobiol 47:195-203

Cole AC Jr (1968) Pogonomyrmex harvester ants: a study of the genus in North America. University of Tennessee Press, Knoxville

Crist TO, Wiens JA (1996) The distribution of ant colonies in a semiarid landscape: implications for community and ecosystem processes. Oikos 76:301-311

Davidson DW (1977) Species diversity and community organization in desert seed-eating ants. Ecology 58:711-724

Davidson DW (1985) An experimental study of diffuse competition in harvester ants. Am Nat 125:500-506

De Vita J (1979) Mechanisms of interference and foraging among colonies of the harvester ant Pogonomyrmex californicus in the Mojave desert. Ecology 60:729-737

Gordon DM (1989) Ants distinguish neighbors from strangers. Oecologia 81:198-200

Gordon DM (1991) Behavioral flexibility and the foraging ecology of seed-eating ants. Am Nat 138:379-411

Gordon DM (1992) How colony growth affects forager intrusion between neighboring harvester ant colonies. Behav Ecol Sociobiol 31:417-427 
Gordon DM (1993) The spatial scale of seed collection by harvester ants. Oecologia 95:479-487

Gordon DM (1995) The development of an ant colony's foraging range. Anim Behav 49:649-659

Gordon DM, Kulig AW (1996) Founding, foraging, and fighting: colony size and the spatial distribution of harvester ant nests. Ecology 77:2393-2409

Gordon DM, Kulig AW (1998) The effect of neighbours on the mortality of harvester ant colonies. J Anim Ecol 67:141-148

Greene MJ, Gordon DM (2007) How patrollers set foraging direction in harvester ants. Am Nat 170:943-948

Haering R, Fox BJ (1987) Short-term coexistence and long-term competitive displacement of two dominant species of Iridomyrmex: the successional response of ants to regenerating habitats. J Anim Ecol 56:495-507

Harrison JS, Gentry JB (1981) Foraging pattern, colony distribution, and foraging range of the Florida harvester ant, Pogonomyrmex badius. Ecology 62:1467-1473

Hölldobler B (1976) Recruitment behavior, home range orientation and territoriality in harvester ants, Pogonomyrmex. Behav Ecol Sociobiol 1:3-44

Jorgensen CD, Porter SD (1982) Foraging behavior of Pogonomyrmex owyheei in southeast Idaho. Environ Entomol 11:381-384

Kugler C (1984) Ecology of the ant Pogonomyrmex mayri: foraging and competition. Biotropica 16:227-234

Kwapich CL, Tschinkel WR (2013) Demography, demand, death, and the seasonal allocation of labor in the Florida harvester ant (Pogonomyrmex badius). Behav Ecol Sociobiol 67:2011-2027

Levings SC, Traniello JFA (1981) Territoriality, nest dispersion, and community structure in ants. Psyche 88:265318

MacMahon JA, Mull JF, Crist TO (2000) Harvester ants (Pogonomyrmex spp.): their community and ecosystem influences. Annu Rev Ecol Syst 31:265-291

Maynard Smith J, Parker GA (1976) The logic of asymmetric contests. Anim Behav 24:159-175

Parker GA (1974) Assessment strategy and the evolution of fighting behavior. J theor Biol 47:223-243

Porter SD, Jorgensen CD (1981) Foragers of the harvester ant, Pogonomyrmex owyheei: a disposable caste? Behav Ecol Sociobiol 9:247-256

Porter SD, Jorgensen CD (1988) Longevity of harvester ant colonies in southern Idaho. J Rangeland Mgmt 41:104107

Robertson IC (2015) Habitat associations and dynamics of Owyhee harvester ant colonies located with slickspot peppergrass populations. Unpublished report on file with the US Fish \& Wildlife Service, Boise ID

Ryti RT, Case TJ (1988) Field experiments on desert ants: testing for competition between colonies. Ecology 69:1993-2003

Ryti RT, Case TJ (1992) The role of neighborhood competition in spacing and diversity of ant communities. Am Nat139:355-374

Schmasow MS (2015) Diet selection by the Owyhee harvester ant (Pogonomyrmex salinus) in southwestern Idaho. MS Thesis, Boise State University

Shattuck SO (1987) An analysis of geographic variation in the Pogonomyrmex occidentalis complex (Hymenoptera: Formicidae). Psyche 94:159-179

Tabor SW (1998) The world of the harvester ants. Texas A\&M University Press, Texas

Tschinkel WR, Adams ES, Macom T (1995) Territory area and colony size in the fire ant Solenopsis invicta. J Anim Ecol 64:473-480

Wiernasz DC, Cole BJ (1995) Spatial distribution of Pogonomyrmex occidentalis: recruitment, mortality and overdispersion. J Anim Ecol 64:519-527

Whitford WG (1976) Foraging behavior of Chihuahuan desert harvester ants. Am Midl Nat 95:455-458 
Table 1. Activity of beta foragers after installing barriers that prevented alpha foragers from accessing their foraging ranges in area between the two colonies. A foraging trail never formed at pair $\mathrm{G}$ even though beta foragers entered the alpha colony's foraging range. Blank cells represent the three cases in which beta foragers did not alter their foraging boundaries after the barriers were added.

\begin{tabular}{|c|c|c|c|c|c|c|c|c|c|c|}
\hline \multirow{2}{*}{ Activity following placement of barrier } & \multicolumn{10}{|c|}{ Nest Pair } \\
\hline & A & B & $\mathrm{C}$ & D & $\mathrm{E}$ & $F$ & $\mathrm{G}$ & $\mathrm{H}$ & I & $\mathbf{J}$ \\
\hline $\begin{array}{l}\text { Days until beta foragers moved into newly } \\
\text { available foraging area }\end{array}$ & 1 & 1 & 1 & 1 & 1 & 1 & 1 & & & \\
\hline Days until foraging trail formed by beta foragers & 14 & 5 & 12 & 39 & 10 & 14 & - & & & \\
\hline
\end{tabular}

Table 2. Response of alpha foragers following removal of the barriers. Nest pair G is not included because the barrier was never removed.

\begin{tabular}{|c|c|c|c|c|c|c|}
\hline \multirow[t]{2}{*}{ Activity following removal of barrier } & \multicolumn{6}{|c|}{ Nest Pair } \\
\hline & $\mathrm{A}$ & $\mathrm{B}$ & $\mathrm{C}$ & $\mathrm{D}$ & $\mathrm{E}$ & $\mathrm{F}$ \\
\hline $\begin{array}{l}\text { Days until alpha foragers were observed entering their } \\
\text { previously-held foraging area }\end{array}$ & 1 & 1 & 1 & 1 & 1 & 1 \\
\hline $\begin{array}{l}\text { Days until alpha foragers occupied the } 50 \% \text { mark of their } \\
\text { previously-held foraging area }\end{array}$ & 3 & 2 & 1 & 1 & 1 & 3 \\
\hline $\begin{array}{l}\text { Days until alpha foragers completely recovered previously held } \\
\text { foraging area. Beta foragers no longer present within the area. }\end{array}$ & 4 & 5 & 11 & 10 & 3 & 9 \\
\hline
\end{tabular}

Table 3. Summary of aggressive contest outcomes between individual foragers from neighboring colonies following barrier removal. Empty cells indicate that no contests of this type were documented.

\begin{tabular}{lllllll}
\hline Outcome of contests between neighbors & Nest Pair & & & \\
\cline { 2 - 7 } & A & B & C & D & E & F \\
\hline Non-lethal & & 5 & 34 & & 2 & 2 \\
\hline Lethal (to one or both combatants) & 1 & 1 & 11 & & 1 \\
\hline
\end{tabular}



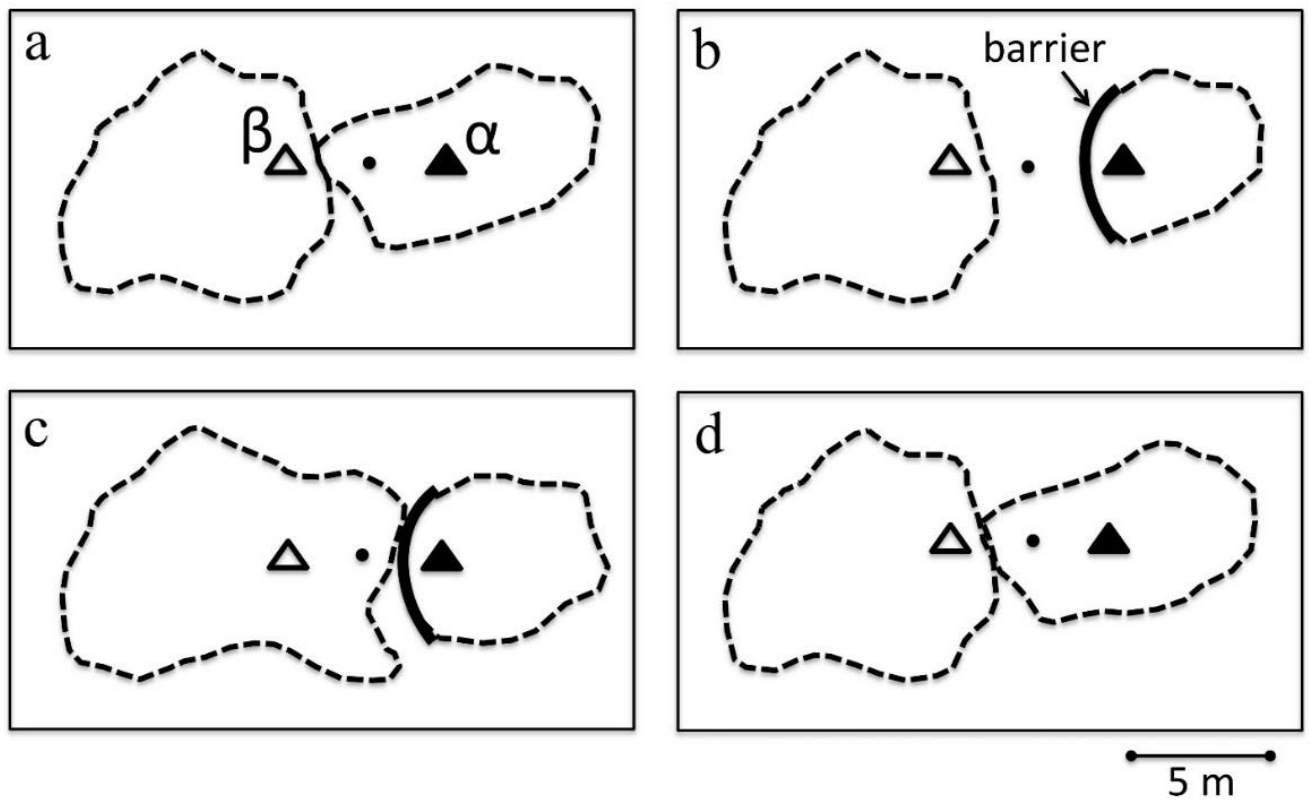

Figure 1. Sequential changes in the foraging territories of neighboring $P$. salinus colonies, using pair $\mathrm{F}$ as an example (see Tables 1 and 2). The alpha and beta nest mounds are indicated by filled and open triangles, respectively, and the dashed lines encircling nest mounds represent foraging territories. The filled circle in each diagram represents the midpoint between nests. (a) Foraging territories prior to experimental perturbation. (b) Foraging territories immediately after the barrier was added next to the alpha nest. (c) Foraging territories 14 days after the barrier was added. Note that beta foragers began entering the uncontested space within one day of the barrier being added. (d) Nine days after the barrier was removed the alpha colony had completely reclaimed its original foraging territory.

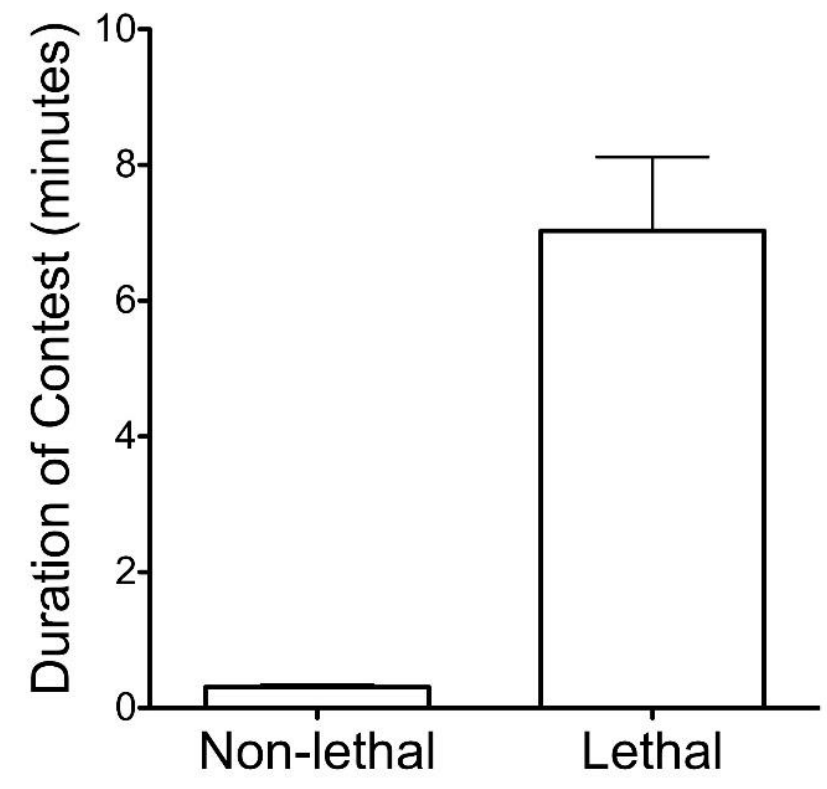

Figure 2. Mean \pm SE duration of non-lethal $(\mathrm{N}=22)$ and lethal $(\mathrm{N}=13)$ contests between individual foragers of neighboring colonies 


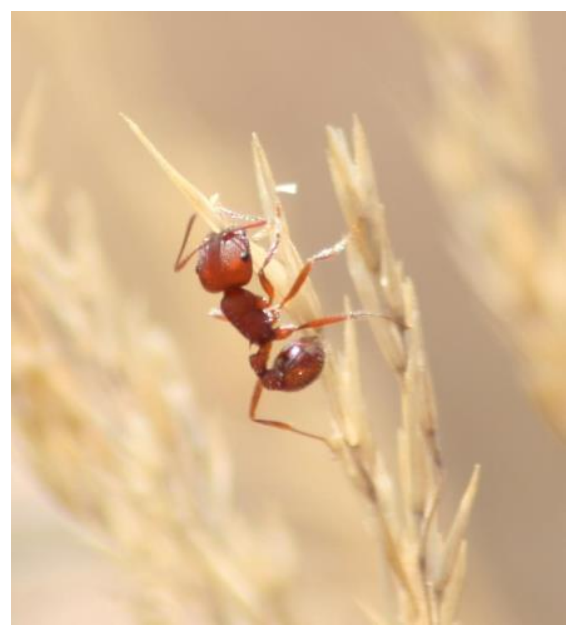

Figure 3.

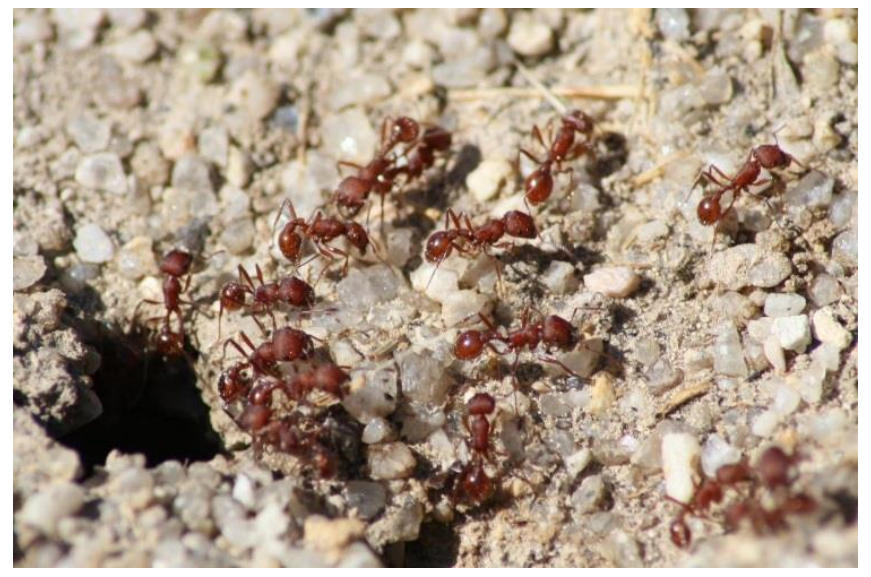

Figure 4.

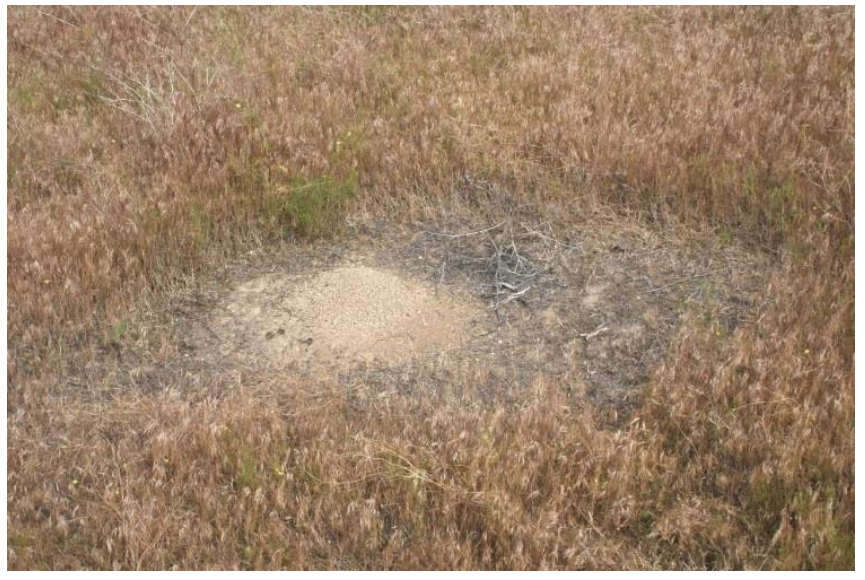

Figure 5. 